\title{
Some Views on Developing Furniture Industry in Yunnan under the Background of INTERNET Plus
}

\author{
Hua-Jie SHEN ${ }^{1,}$, Jian QIU ${ }^{1}$ and Han LIU ${ }^{2, b}$ \\ ${ }^{1}$ School of Materials, Southwest Forestry University, Kunming, Yunnan Province, China \\ ${ }^{2}$ Dongguan Polytechnic, University Road, 3rd, Songshan Lake zone , Dongguan, Guangdong \\ Province, China \\ E-mail: ahuajieshen@163.com, bdr-liuhan@163.com
}

Keywords: Internet plus, Furniture in Yunnan, SWOT, Innovation, Design.

\begin{abstract}
The development of Yunnan's furniture has been lagging. In order to seek the route or method for developing the furniture industry under the background of Internet plus, the aspects of key points of its advantage, and disadvantage, and opportunities, and threat were analyzed. The four were dipped out through mining the implications of "Internet plus" and "Internet plus Economic", by means of SWOT analysis. After strategy analysis, it come to the development countermeasures that to propose swagger, to overcome short, and to focus on design are best choice to pool the new furniture era, contacted closely to essence of innovation, combined by the essentials of design.
\end{abstract}

\section{Guidelines}

In the passing ten years, with China National Furniture Associations collaborative development and planning, the furniture industry in Yunnan province undergoes from major bridgehead to one belt one road directive. Emergence In these years, some industrial parks were emerged, such as Jinning furniture industrial park. It also owns two exceptional titles called as China national wood carving furniture industrial foundation (Jianchuan County) and China mahogany furniture industrial foundation (Ruili County). Meanwhile, Chinas furniture is well known of overcapacity, especially with the quick growth of internet economy. However, how can the internet economy stimulates Yunnan's furniture industry to overcome the plight, even to make it possible to be furniture giant in the southwest of China. In the strategy of one belt one road, Yunnan is designed to play its role face to southeast Asia. So, to build up a new and different situation of its furniture is a topic worthy of discussion.

\section{2. "Internet Plus" and "Internet Plus Economy"}

According to a newly report [1], till 2015 the number of netizens in the mainland of China turn to more than $688 \mathrm{~m}$, and the internet penetration rate of $50.03 \%$. Mobile terminals become a powerful engine, and e-commerce and other internet products and the operating mode are of great change and innovation. And as early as in 2015 during the "two sessions", prime minister Ke-Qiang Li proposed the "Internet plus" plan of action for the first time [2]. The essence of the plan is to add internet to the traditional industry. It does not mean to add one and one, but mean to make the internet deeply integrated with traditional industry, using information communication technology and internet platforms, to create a new development ecology.

\subsection{Connotation of "Internet Plus"}

The essence of "internet plus" is to make the traditional industry turn to be online and digital [3]. This kind of business model can collaborate with minimum cost flow and exchange among the main bodies at any time in the upstream and downstream industries, changed in the past only closed within a department or enterprise traditional mode.

"Internet plus" can be regarded as a strategic upgrade version that named as "two national combination", which is translated as industrialization and informationized. In other words, it not 
only means industrialization, but also means to treat internet as core characteristics, extracted from the Internet as the of current informationized development, comprehensive integrated with financial, industrial, commercial and service industry. It must be known that two is bigger than one and one in this integration, for it does not being overlapped simply. And innovation is the highly key factor that it makes plus sense. Furthermore, "internet plus" can play more significate roles particularly put into the strategic of one belt and one road.

\section{2. "Internet Plus" Economy}

"Internet Plus" Economy. "Internet plus" economy mainly refers to the internet with manufacturing, financial industry development [4-5], etc.. It also refers to the transformation and upgrading of traditional industries rely on the internet. It ask people to accelerate the internet economic penetration and fusion of the traditional industry. It ask people to create new economic growth point. It ask people to promote the industrial structure and to exchange economic transformation and social development of continuous.

To read it and its economy, it is needed to analysis the true mean of innovation, a key word of economic development, from the perspective of the innovation and its connotation. In order to understand the essence of the model of "internet plus" and its meaning to innovation, Wen-fan Zheng [6] used the theory of value concept of science and technology to discuss the model and the innovation. Xiang-dong Wang [7] also emphasized the trump role of innovation when the "internet plus agriculture" was studied.

Relationship between "Internet Plus Economy" and Traditional One. Reported on a speech [8], Academician He-shuan Wu underlined that to develop manufacturing industry normally is the foundation of the "internet plus" industry. And it is easy to keep the main point that to unscramble the relationship between the new economy and the older one is necessary before one start to study how to give birth to a traditional industry to open a new route in the new era surrounded by internet plus.

In the older one, innovation mainly played its role by slowly improving the production efficiency and technical innovation, as original technological one owned by suppliers. Distinctively, in the newer one, it mainly plays its role by seeking more and more iversification, personalized to meet consumers' needs, in which the dynamic changes of the demand can drive innovation in high speed. Besides, the innovation makes it easier for enterprises to keep in or out the market, and the market structure is characterized by dynamic competitive monopoly characteristics, which can be read from table 1 .

Table 1 Distinction between internet plus economy and traditional one

\begin{tabular}{lll}
\hline & Internet plus Economy & Traditional Economy \\
\hline Need & Homogeneous & Heterogeneity \\
\hline Mode of production & $\begin{array}{l}\text { Standardized and large-scale } \\
\text { Large-scale }\end{array}$ & $\begin{array}{l}\text { Personalized, customized } \\
\text { production, different scope }\end{array}$ \\
\hline Barriers to entry & Higher in and out & Lower in and out \\
\hline Scale of market & $\begin{array}{l}\text { High transaction costs, } \\
\text { asymmetric information } \\
\text { Regional and global }\end{array}$ & $\begin{array}{l}\text { Low transactionsufficient information } \\
\text { Market scope to further expand }\end{array}$ \\
\hline Division of labor & Industry division & Deepening and refining in production \\
\hline Enterprise organization & $\begin{array}{l}\text { Big companies, and vertical } \\
\text { integration }\end{array}$ & Network organization \\
\hline Structure of market & Oligopoly, monopoly & Competitive market \\
\hline Strategy of competition & Price, numbers & Difference, quality \\
\hline Innovation & $\begin{array}{l}\text { Slowly, production } \\
\text { technology }\end{array}$ & Quickly, meet needs \\
\hline
\end{tabular}

\section{SWOT Analysis to Develop the Furniture Industry in Yunnan}

SWOT Analysis contains strength, weakness, opportunity and threat, four key factors used to study research object. 


\subsection{General Situation of Yunnan's Furniture}

As the second largest of timbers resource, Yunnan owns about 1.55 billion cubic meters standing timber [9]. But the furniture industry in it has been unable to become stronger, could not be better and faster like the any other province neighbor that are able to create their own brand. Instead, industrial development is being replete with the path of selling resources, such as timber, bamboo. From figure1, it is found that the products output value accounted very low, and hard to known which company can reach its aim to of 100 million. Looking at the market, the blood-forming ability of local enterprises is weak, and the major markets are mainly marketing the products engaged in foreign companies [10].

On the other hand, Yunnan reached great mark in recent years, the samples can be taken Yunnan pan-Asia furniture industry park (Jinning county), which was planned in 2010 and was constructed in the followed years. And China national wood carving furniture industrial foundation (Jianchuan County) and China mahogany furniture industrial foundation (Ruili County) as well. The three were sharing the heavyweight of base industrial parks, around by more than ten. Besides, Kunming, will form Chinas emerging furniture distribution center and furniture industries effective venue.

\subsection{SWOT Analysis}

Strength. Advantage of resources. From figure 2, in 2014, the wooden furniture was the main force of furniture in China, but was just accounted for up to $65.51 \%$ in Yunnan. Nicely, the ratio sounded that the development of furniture manufacturing in Yunnan was created and larger than some of others.

Basement. More than more than 3,000 local furniture companies were developing slower in the passing decades than that in other provinces, even though there were still owing some immense enterprises which had the needed basement to pour their energy into standing up "Qualitative Change". Meanwhile, in the past five years, the construction of industrial parks, especially in Jianchuan and Ruili, had an increasing number of large-scale enterprises year by year. These enterprises are brewing strong blood, such as enhance connection with developed areas, personnel training, attention to design, and so on. In addition, the "Pan-Asian furniture Expo" creates sustainable building for corporate communication, and for marketing communication, and personnel exchanges as well.

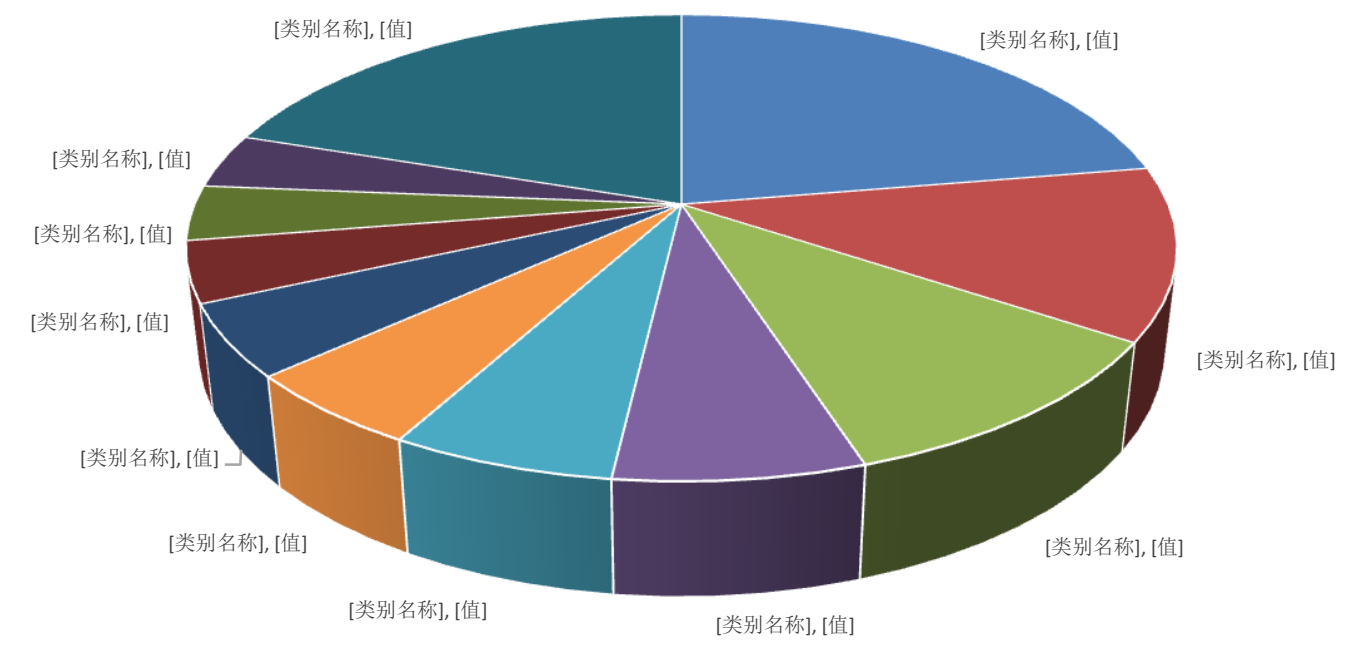

Figure 1. Provincial furniture production value in China in 2014 


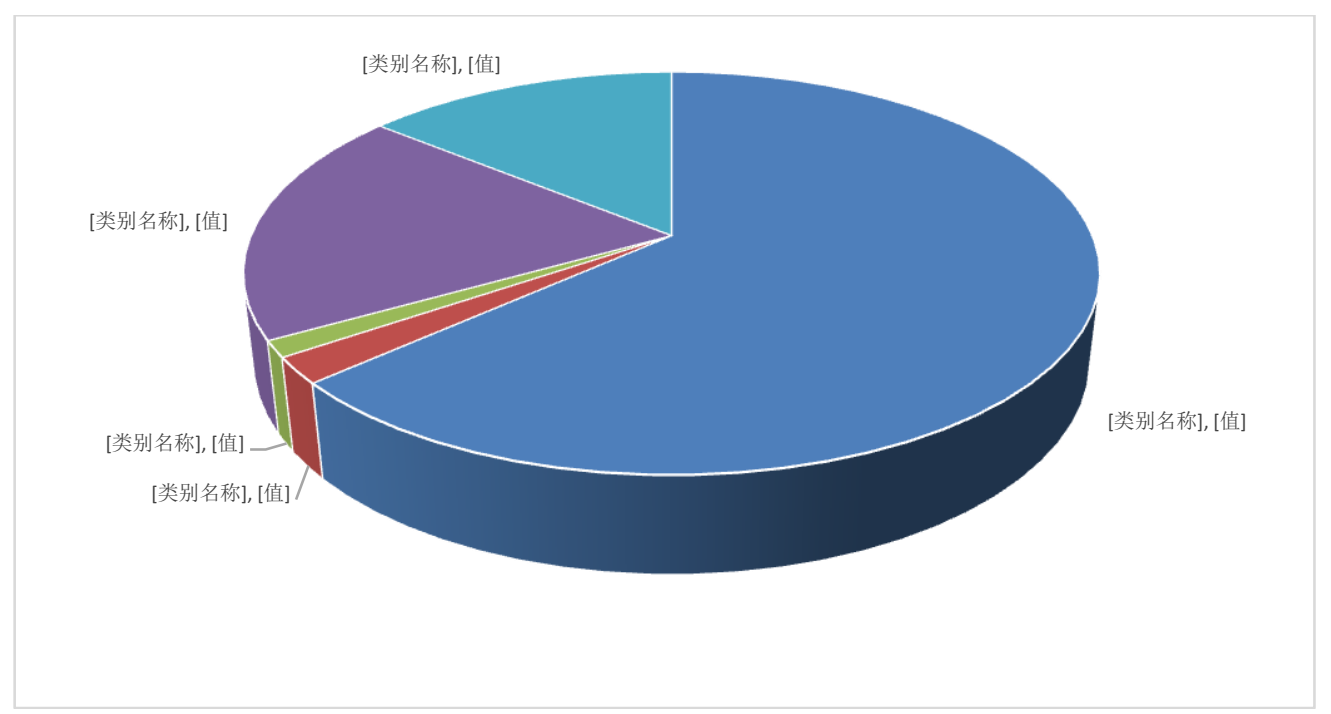

Figure 2. Furniture production value in different types in 2014

Good human relations. Undoubtedly, it is hard for the furniture industry to make any step without any factor of human being, and it is just the right and good human relations that can make things sense, especially when the things own favorable situation formed by time and location. Take Central South University of Forestry and Technology for example. In the passing three decades, the university continuously delivers graduates into Guangdong province where forms enviable furniture industry. Fortunately, there are several colleges develop their furniture major education for more than ten years, such as Yunnan Forestry Technological College and Kunming University of Science and Technology. And as the only one of forestry university in the southwest of China, Southwest Forestry University started its furniture major rightly in 2011. What is more, Yunnan Association of Designers was successfully setup in 2015, and most of the furniture designers in Yunnan have the needed platform to exchange their motion and others. But it is still a long way for Yunnan to form better situation.

Weakness. Weak industrial statement. Although it planed and constructed two industry park in good vision, it is still hard for it to form the anticipated and extensive condition, for the industry is still immature.

Inconvenience of logistics. It is well known that Yunnan province is located in the inland, and subjected to geographical conditions, it forms a great deal of trouble in respect of logistics services. On one hand, local manufacturing companies or outside service providers are contributing to increased survival time in the industry costs. On the other, most of the furniture marketing is easy to weak its sense of service and to reduce the service level for transportation factors.

Weak in awareness of place. Another one of the most obvious difficulty the furniture industrial development in Yunnan province owns is weaken developed of market. When face with advertisement, most of the companies would to pay more attention to the sailors but not to customers, and the right information is hard being read in the advertisement which is lack of accurate brand orientation and clear target population.

Rare of design. First, lack of originality. It could be extend to the condition of weak manufacturing design capability, lack of brand management and marketing strategies, and rare of origin design goes with ignore of originality in market. Many companies like to wearing a vest and managing setup low price. Second, copycat. Furniture enterprises in Yunnan follow others severely. Once they get any information of what is good at selling in other provinces, they would pour into producing quickly, seldom think about what is just people in Yunnan want. Those dilemma of design are easy to be turned into stumbling block.

Few focus on quality and brand. Presently, the brand building is still at an early stage of furniture enterprises in Yunnan province. And there is still several problem in the building. Firstly, some bodies just think about how to build their brand when they face the developing question. Secondly, 
once they get new way to keep fortune, most of them forget all of brand quickly. Thirdly, with the two former factors, there are so few brand that the citizens known seldom.

\section{Opportunities}

Policy. Undoubtedly, the One belt one road Policy significantly gives Yunnan new opportunities in developing furniture, and broads the route as well. At the same time, the Urbanization also delivers Yunnan the opportunity to expand more space. And policy support of the furniture industry of Yunnan province had long been a blank, compared with that in Sichuan which was developing its furniture quickly in the passing years benefit from the support of the government that enacted some meaningful policy. A bit is better than nothing that the government in Yunnan also started the step and several policies were delivered such as Views of the Yunnan Provincial people's Government on speeding up the development of forestry industry and Kunming municipal people's Government on speeding up the development of forestry industry. And now Furniture and wood processing have been included in the scope of planning focus on the development of industry.

Resource. Though it owns abundant of forest resources, the countries policy of To facilitate afforestation makes it hard to the enjoy the large scale of forestry development and utilization. And people put their eyes into researching how to develop the resource normally and meaningfully. As a good sound, the project of Sino-Myanmar oil pipeline could give birth to the furniture related.

\section{Threat}

Macroeconomic environment. With the macroeconomic environment, it is arduous for most cities to develop their furniture these years even to Shenzhen which is treated as the weathercock city, and there is overcapacity problem in China's furniture industry as a whole, which is continuously developing. What is more, the implementation of new policy Wood based panel industry emission standard should be a severe examination.

Marketing mode. Everyone has his idea about how to reach up to the success on marketing mode in the Internet plus economy. But after all, it must be known that the traditional one is being changed little by little now.

Traditional thinking. Large number of the companies are slower than other provinces in information construction. They think it is not the high time to develop new technology for others all not welcome the newer.

Knowledge storage. At present, the furniture industry in Yunnan province structure is unreasonable, talent designers are draining out, and it is hard for the government to keep the storage needed to develop the furniture economy.

\section{Development of Strategies}

\section{Exalt the Strength}

Enjoy Policy Sufficiently. Meaningful policy is a guide to industry. To develop the furniture in Yunnan, it need to make the policy sense first. So, it is better for people to build the industry park normally to get ready to form a new cluster in market and manufacturing. Meanwhile, the government could transmit the products together with the culture into South Asia where the education, market, service and other related to furniture are needed.

Orderly Development of Resources. The local manufactories could find the right one of develop mode, could exact local resources with support of local policy, such as policy on developing national wood carving furniture, rosewood furniture, bamboo and rattan furniture, also the newer one that connected to the development of petroleum.

\section{Last the Human Resources}

Professionals. First, to increase exchanges and cooperation with local college teams, to take advantage of outstanding professionals, to enrich the furniture industry in Yunnan team of managers, designers, and so on, to mine local graduates, etc. are all good to form a healthy and professional 
state. Second, a good "design of Yunnan" platform could cultivate operational capacity, and could speed up the exchange of personnel.

Structure of HR. As a special industry of low concentration, it is easier for the furniture companies to in or out, and it is easier for the structure of HR to turn out to be unreasonable.

\section{Insufficient to Overcome}

Make up with Industry Cluster. Till now, Yunnan has not yet formed a real furniture industry cluster and saved in a weaker position in the national competition, and it is more difficult for many manufactories to survive in the tide of transition. And no matter how the internationalization forms, the companies regional market characteristics remains. So if the companies have neither size nor quality, the emerging seedlings with industry cluster would be nipped in the bud by foreign powers.

Scientific Planning Industrial Park Construction. Industry park is one of the best way to form industrial cluster. The construction of the park must be built base on the clear industry positioning, reasonable allocation of industrial resources, needed foundation and factors. It is always a professional work to study how to build the park, compared with that in city design that need not to think more about every manufactories condition, particularly of different product planning, public platform, and so on. But as a shame, there is seldom park of the right location that meaningful to the industry, and this is maybe the reason that Yunnan slow down its step to form the cluster.

What worthy of praise is that there are still some companies struggle to survival in the serve competition surrounded by excess capacity and depressed market. They need to choose whether to continue its success of previous "all-inclusive" to ensure "stability" and "foundations", or to cut negatives resolutely like a strong man to broken his wrist quickly.

\section{Emphasis on Design}

In The era of Internet plus economy, is no longer a blind eye era, but is only quality is the essence of success. Quality, innovation, better designed, quality creates brand.

Options on the Process of Design. In condition of excess capacity, the manufactories best route is to upgrade its quality, to enhance its competitiveness in the market. And design is the base route to achieve competitiveness and to add value, though the whole countries condition is different from here to there, that except Shenzhen, many of the zones have the unobvious starting line. When more and more eyes were put into focusing on design, than the true value was get there. But look back into the pass, it is hard to get the answer that which company would like to treat design seriously.

Unswervingly Taking the Road of Quality and Brand. Wrong-competition is a direct consequence of overcapacity. Everyone knows that in the normal operating condition, pricecompetition make one like to change fake as good. With rational consumption, consumers behavior has changed. People are willing to pay a high price into the true brand, for they could assure that the true brand has the true quality. Unfortunately, the number of brand is too little in Yunnan.

\section{Final Manuscript}

Despite decades, the development in Yunnan still lag. The Internet plus brings infinite opportunities for regional economic development, and also brings a number of challenges. On the road to transformation, furniture industry in Yunnan is also at a loss. To research the route to develop the furniture industry with the background of Internet plus, the SWOT analysis was used to analysis Yunnan province furniture industry development status, and to point out the advantage, disadvantage, opportunities and threat. Then it noticed the high point of innovation, combined essentials of design, and it proposed swagger, and focus on design.

\section{Acknowledgement}

This work is supported by National Nature Science Foundation of China (No.: 31570555) etc. 


\section{References}

[1].CNNIC. The 37th report of internet development in China(2016). http://cnnic.cn/gywm/xwzx/rdxw/2015/201601/t20160122.html.(in Chinese)

[2].China News network. Li's Government work report at the opening session of the national people's Congress(2015) http://www.chinanews.com/gn/2015/03-05/7103283.shtml. 2015-03-05(in Chinese)

[3].J.J. NING. Background, connotation and main content of the Internet plus action plan. EGovernment. Vol06(2015),pp.32-38. (in Chinese)

[4].L. C. ZHAO. Internet economy and China's industrial restructuring and upgrading. Contemporary economics and management. Vol37(2015),pp.54-59. (in Chinese)

[5].S.X. HUANG. China's film industry and cultural reflections. Journal of Shanghai University of technology. Vol32(2015), pp.23-39. (in Chinese)

[6].W.H. ZHENG, M.W. LIU. Scientific value and "Internet +" action on the role of innovation and entrepreneurship. Journal of Northeast University. Vol17(2015)567-572. (in Chinese)

[7].X.D. WANG. Internet plus agriculture. Times report. Vol2(2016), pp.333. (in Chinese)

[8].W.B. CHEN. Manufactory is the basement. Shenzhen daily, Nov. $17^{\text {th }}$, 2015. (in Chinese)

[9].H.J. SHEN, Z.J. TANG. First undergraduate furniture major students were started in SWFU. Furniture and interior decoration. Vol10(2011), pp.46-47. (in Chinese)

[10].J.W. LI. Think on the development of Yunnans furniture. Vol5(2014), pp.62-63. (in Chinese) 